\title{
Integration of health care delivery in the Eastern Mediterranean Region of the World Health Organization
}

M.I. Al-Khawashky'

SUMMARY This paper reviews developments in the integration of health care delivery in the Eastern Mediterranean Region. It describes the integrated intersectoral support of socioeconomic community development (district health systems and basic development needs), the functional intrasectoral integration of health services and interventions, and health resources integration.

\section{Introduction}

Since the adoption of primary health care (PHC) as the only approach for achieving health for all more than two decades ago [1], Member States of the Eastern Mediterranean Region (EMR) have diverted more attention, political support and national resources to strengthening PHC services to ensure equitable access to sustainable quality health care for the entire population, with varying degrees of success. While health planners and administrators envisaged that integration of the components of PHC would prove a cost-effective approach to health care delivery, many difficulties have been encountered in achieving such integration [2].

These difficulties involved the semiautonomous vertical programmes established with specialized infrastructure, alongside of a general health infrastructure providing curative services and a variable range of preventive services. These vertical programmes were intended for the control of specific priority health problems, such as smallpox, yaws, malaria, tuberculosis, leprosy, during the 1960 s or for the provision of basic health services for specific national target populations, such as mothers and children. The transition required restructuring these vertical and basic health services programmes into an integrated infrastructure capable of providing adequate, cost-effective promotive, preventive, curative and reconstructive quality health care services to all the population involving all levels of available health care facilities and personnel as well as the community and other health-related authorities. Some of these difficulties could be also attributed to national factors, such as lack of the necessary political decision and recognition of the positive impact of integration on health resources utilization and on the ultimate outcome of the health system, an absence of shared objectives among health professionals and workers at different levels of the health system. lack of staff motivation or personal incentives to contribute to an integrated approach, and inadequate development of the health infrastructure,

'Special Adviser to the Regional Director, World Health Organization Regional Office for the Eastern Mediterranean, Cairo, Egypt, and former WHO Representative, Egypt. 
particularly at the peripheral levels. Moreover, the operational difficulties within countries have often been compounded by the continuing preference of some international donor agencies to support categorical programmes with autonomous infrastructures that concentrate on a single set of activities in isolation of the broader general health services.

While the health care delivery systems were undergoing the transition to the PHC approach, some trends emerged in the 1990 s in response to global changes, economic reform and structural adjustment, as indicated in the United Nations Development Programme (UNDP) annual world development reports for 1996 and 1997 [3,4], and the World Bank report of 1993 [5] where the concept of "disability adjusted life years" (DALYs) was introduced as a quantifying measure of health outcome with regard to the global burden of disease [6]. Such trends, in part, initiated the process of health sector reform [7] in both developing and industrialized countries, which led to the following shifts in focus.

- Orientation towards market econumics and privitization or private/public mixing of health care in view of the escalating costs of health services and technologies.

- Optimal use of the diminishing national resources for health to ensure sustainability and cost-effectiveness of health programmes that respond to the needs of all the population, in parallel with an increasing role of government health authorities to coordinate and monitor all health care services.

- Increased coordinated cooperation between health and other health-related sectors to address problems related to health, economic and sociobehavioural determinants, such as poverty, food. shelter, water, sanitation, accidents and environmental hazards, and healthy lifestyles promotion.

- Clustering or packaging of promotive, preventive and curative health technologies and interventions to meet the needs of specific groups, such as children, women, mothers/babies, villages, schools.

- Horizontal and vertical networking of different types and levels of services within the health system to ensure adequate health care and two-way referral of patients and/or health problems at the most economic cost and with the best possible use of resources.

- Involvement of the client (individual, family and community) in self health care, priority setting and resources allocation.

In consideration of the aforementioned trends, the WHO Eastern Mediterranean Regional Office (EMRO), in line with WHO policies and the resolutions of its governing bodies, and through close consultation and constructive dialogue with the health authorities of the Member States of the Region, explored, innovated, initiated and assessed different approaches to health sęrvices integration, from which several pathways emerged.

\section{Integrated intersectoral support} to comprehensive socioeconomic community
development

\section{District health system}

Based on the PHC principles and approachcs, and considering health as administratively and technically central and conditional to development, the district health system (DHS) [8] appruach was introduced 
in about half of the Member States of the Region. It aims to improve the health status of the population through intrasectoral coordination of the health services supported by intersectoral collaboration with the health-related sectors and local community participation.

The wilayat (district) health system was initiated in Oman in the mid-eighties and by 1997 all the districts of the 10 regions of the country had an efficient DHS in place. The system was evaluated in one district of each region in 1997 (A. Abdullatif, personal communication, 1998). It has provided useful information for improving PHC services through total quality management and enhancing the role of private and other health-related sectors and nongovernmental organizations (NGOs) in its delivery.

The integration of PHC services under the umbrella of DHS was initiated in four districts in Pakistan (M.R. Sheikh, personal communication, 1999). The protocols on quick appraisal techniques for DHS developed by EMRO were used and adopted to the local requirements. Similarly and in the carly nineties, DHS was initiated as a priority for health systems development in Egypt. Programmes for women's health and development, child health, reproductive health, including family planning, and other population activities, which are supported by different United Nations (UN) [WHO, United Nations Children's Fund (UNICEF) and United Nations Population Fund (UNFPA)] and bilateral [USAID, Danish International Development Agency (DANIDA), Finnish International Development Agency (FIDA)] and others agencies have been integrated and nationally coordinated and managed in more than 30 distriots in support of family health care which has recently been adopted by the government. These include 12 districts in 3 underdevcloped governorates in upper Egypt covered by UNICEF, 3 districts ( 2 in upper and 1 in lower Egypt) covered by UNFPA, and 10 districts in 9 governorate covered by the Ministry of Health with WHO support. Here, 18 different WHO collaborative activities are integrated with PHC services to strengthen the health system infrastructure and provide sustainable quality health care for all to ensure health promotion and control of health problems common to individuals, families and the communities. The national Social Fund for Development is supporting the implementation of DHS in 6 districts. Moreover, the health sector reform process, initiated in 1998 with World Bank and European support, adopted DHS as the operational strategy for the provision of a package of integrated, cost-effective, essential quality health care services covering children, women and reproductive health and common communicable and noncommunicable diseases in about 25 districts of the 3 governorates selected for the implementation of the first phase of health sector reform by the end of 2003 .

In the war-torn Afghanistan, WHO has extensively assisted the national authorities in the introduction and expansion of DHS in collaboration with local tribal and religious leaders [2]. It has also supported numerous training activities to build the capacity of DHS human resources.

After the civil war in Lebanon, WHO supported the assessment of PHC services in the underdeveloped districts [2]. The subsequently formulated plan for strengthening and integrating these services has successfully attracted financial and technical support from many bilateral and multilateral donor agencies.

The government of Sudan has consolidated and expanded the integrated health care approach and introduced new initiatives to strengthen the personnel capacity and improve planning and monitoring of DHS. 
The Islamic Republic of Iran has recently initiated the process of total quality management for improving the standards and efficiency of health services already integrated at the district and community level $[2]$.

The concept and methodology of DHS have been recognized as central to the master plan of action developed recently for revitalization of PHC services in the Republic of Yemen with strong political commitment [2].

Apart from these aforementioned examples of WHO-supported initiatives, DHS has been implemented with appreciable success in most, if not all, the member countries of the Gulf Cooperation Council through cooperation and intercountry coordination by the Health Ministers, with WHO advisory support as required.

\section{Basic development needs}

Thailand adopted the basic minimum needs approach for improving the quality of life and addressing health problems among deprived populations through socioeconomic development facilitated by organized community mobilization and intersectoral cooperation. Based on its experiences, and after field exposure of multisectoral national teams from most of its Member States to this experience in the late eighties, EMRO started to focus on basic development needs (BDN) as an innovative approach for accelerating progress towards health for all.

Major progress has taken place over the past 10 years in implementing the programme, and 10 Member States of the Region (Afghanistan, Djibouti, Egypt. Jordan. Morocco, Pakistan, Somalia, Sudan, Syrian Arab Republic and the Republic of Yemen) are at different stages of its implementation at present. The approach opens the door for cooperation between all stakeholders, enhancing solidarity, alliance and partnership at different levels of work, and achieving a higher degree of relevance and sustainability because its activities are community-centered and community-led, and they address poverty as the root of ill health and other social evils.

After sending rapid field observation missions to Pakistan, Somalia and Sudan, the Regional Office held a consultation in June 1998 where the 10 country experiences were reviewed in depth and achievements, constraints and challenges were documented [9]. Some of the achievements of this programme that were identified included the high degree of community mobilization, organization and empowerment, the strengthened intersectoral collaboration. the promotion of solidarity, democratization and self-reliance even in difficult , situations of war and civil conflict, the increased accessability to and coverage by essential public health services, healthy lifestyle promotion, women's empowerment and development, increased income and better nutrition as a result of a wide range of income-generating activities, improved education (particularly of girls), vocational training and environmental sanitation. Moreover, the BDN programme has achieved success in attracting new partners among international agencies and NGOs and has demonstrated its applicability in both rural areas and urban settings.

Among the constraints and challenges noted by the consultation were: the need for adequate operational research and documentation, the need for more systemic approaches in planning, implementation and evaluation, the need for more experience in microcredit schemes management, insufficient support from other UN agencies and international organizations, and a lack of training materials and modules, particularly in local languages. 
Healthy citles, villages and communities $[2,10]$

Healthy cities

Based upon experience gained from implementing healthy cities projects in many European countries, EMRO introduced this programme to its Member States in 1990. The concept attracted the keen interest of professionals, city authorities and national decision-makers of health and other sectors. The programme concentrates on integrated, comprehensive, environmental health activities that include sanitation, water supply, drainage, upgrading of streets, food markets and slaughterhouses, and food safety. Eight countries of the Region have adopted this approach with varying degrees of progress and joint national/international and NGOs contribution.

Afghanistan implemented the approach in Jalalabad assisted by WHO and further supported by the World Food Programme (WFP). Cyprus started it in Pathos and subsequently expanded it to four other cities, namely Alglanjia, Strovoles, Polis and Latsia. An extensive healthy cities project is progressing in Fayoum Governorate in Egypt. It was initiated with resources from EMRO and is maintained by WHO/UNDP/ LIFE (Local Initiative Facility for Urban Environment) resources and nationally by more than US\$ 8 million of multisectoral and community resources. It is managed by a healthy city task force according to an elaborate plan for the improvement of water supply, sanitation, housing, the upgrading of streets and food market facilities, income generation, health education, healthy schools and other public facilities, and the physical and functional upgrading of the health services. Similarly a healthy city/women's development project has been initiated in Alexandria, Egypt for solid waste management and women's empowerment. It is a WHO collaborative activity with the local city district, and substantial support has come from the NGO, Plan International.

In the Islamic Republic of Iran, another successful experience with a healthy cities project in south Teheran was initiated with WHO support. The activity has spread to 12 other cities, in addition to 2 other districts in Teheran. A national programme was established, supported mainly by national multisectoral resources and managed by a high-level ministerial council, chaired by the Minister of Health and Medical Education and with members from a number of concerned ministries and the Mayor of Teheran. The healthy city programme has also been adopted nationally in both Tunisia and Morocco with minimal WHO support. With political and financial support received from the highest authorities in Tunis, the programme has expanded actively to seven cities. A national multisectoral healthy cities coordinating committee was established in Morocco to implement the programme activities in four cities. Later this programme was integrated into a major national campaign under the banner of "Clean Cities" launched by the Ministry of Interior. - In Pakistan, extensive healthy cities activities are ongoing in the city of Quetta, supported by the WHO/UNDP's LIFE Healthy City Projects. An attempt to expand it to other cities failed because national expectations of large financial support from external resources were not realized. Similarly, a project initiated with minimal WHO financial support in the city of Zarka in Jordan has not progressed satisfactorily for the same reason.

\section{Healthy villages}

To include physical and social factors that affect health at the village level, EMRO introduced the concept of healthy villages in 1990 as a tool to enhance PHC to achieve 
health for all in rural communities. It addresses the requirements for integrated, sustained socioeconomic rural development, including health, education and income generation, based on active community participation and organized intersectoral cooperation. Priority is given to health as an entry point by upgrading the existing physical and functional PHC structure and focusing on supporting environmental health determinants, namely water supply, sanitation, solid waste management, housing, village cleanliness and healthy lifestyles.

Since the early 1990s, the programme has been successfully implemented and sustained in Egypt and the Islamic Republic of Iran, while it is underway in Afghanistan, Oman and the Syrian Arab Republic. In Egypt it started in 1993 as a WHO/ UNDP/government project entitled " $\mathrm{Em}$ ployment and Sanitation in Healthy Villages". One main village and 4-6 satellite villages were selected in each of the 26 governorates of Egypt for its implementation by the Organization for Reconstruction and Development of Egyptian Villages (ORDEV) which is presently under the Ministry of Rural Development. The success of this experience urged the government to adopt the concept nationally and allocate resources to cover all the villages of Egypt by the year 2010 under the title of shrouk (sunrise) programme [11]. The past 5 years have witnessed its expansion to more than 600 villages representing about $15 \%$ of the total number of villages of Egypt.

In the Islamic Republic of Iran, a dynamic and extensive rural environment programme started in the early 1980s [2]. The scope of the programme was modified and expanded in the early 1990s to include other socioeconomic components as an integral part of the PHC system under the title of healthy villages. In this system, the health houses, staffed by two well trained community health workers (behvarz), are the first level of contact for people in the rural areas. The behvarz respond to the socioeconomic and health basic development needs with organized collaboration of the community workers designated by other sectors and the active involvement of the community through the village council.

Healthy schools

Schools were recently focused on in Jordan, Syrian Arab Republic and Egypt [12] through WHO-supported projects to illustrate health promotion and environmental protection concepts and activities and to use students as a vehicle of knowledge for their families and the local community.

Among the outstanding outcomes of WHO collaboration in this respect are the launching in Egypt of its National Programme for Health and Environmental Promoting Schools in September 1999, the organization of the Regional Conference in Cairo, Egypt by the Arab Council for Childhood and Development, on school health and environmental promotion in the Arab States in November 1999, and the subsequent establishment in May 2000 of The Arab Organization for School Health and Environmental Promotion with participation of 12 Arab countries which is being hosted by the Lebanese Society ajyaluna (our generations) in Beirut.

\section{Functional intrasectoral integration of health services and interventions}

Many forms of functional integration of health services and interventions have been practised in the process of national health systems development in the Member States 
of the Region, with the aim of achieving optimal use of health resources, increased efficiency of services and more convenience to the consumer.

In most cases, integration has been effected horizontally among intrasectoral health programmes which provide services at the same level of health care, particularly PHC and address a specific vulnerable target population, such as children and mothers through maternal and child health care centres. Vertical integration of these services between primary, secondary and tertiary levels of health care has also been attempted with varying degrees of success. Such integration requires a well designed, simple, bidirectional referral system of both patients and health problems between the levels. In addition, health services integration between the public, private and NGO health care providers has been attempted [13], although with limited success in most countries except Lebanon, where it has been in practice for a long time and is more the rule than the exception.

Multifunctional maternal and child health centres were established during the 1960 s as essential components of basic health services. These centres served as nuclei around which other components of PHC services adopted in the early 1980 s were attached [14]. They also embraced some of the ongoing vertical programmes such as the Expanded Programme of Immunization (EPI) which in itself represents a horizontal integration of preventive measures against vaccine diseases. However, while maternal and child health care was running smoothly under the umbrella of PHC [15], some of the donor agencies (USAID) introduced the resourceful vertical programme of "child survival" [16] to encompass vertically four of the WHO programmes of EPI, control of diarthoeal disease (CDD), acute respiratory infections
(ARI) and nutrition. About the same time, the Safe Motherhood Initiative [17] with its different components was introduced by WHO/UNICEF as a vertical programme to boost maternal health care at different levels of the health system, particularly PHC. While these two programmes have contributed positively to the health of mothers and children, they have marginalized to some extent the capacity and credibility of the other PHC services and their professional providers. However, by the beginning of the $1990 \mathrm{~s}$, serious attempts were taken to integrate most, if not all, these programmes horizontally to address all health promotive, preventive and curative issues of mothers under the integrated programmes of women's health and reproductive health, and to integrate all of these with those of child health in one package entitled mother/ baby package (WHO) [18] or healthy mother/healthy child package (USAID) [19] and its Mother Care [20] bridge activities in collaboration with UNICEF.

Another form of integration of health services which aimed to reduce maternal morbidity and mortality and the urgent need for family planning was introduced after the International Conference on Population and Development held in Cairo in 1994. Health care components of reproductive function were universally adopted as an integrated package including information and education, premarital counselling, perinatal care, family planning, infertility management, genital tract infection, antitetanus vaccination, nutrition, infant breastfeeding, sexually transmitted diseases and human immunodeficiency virus (HIV) infection. The experience is gradually gaining momentum in most countries of the Region through WHO joint collaborative efforts with UNFPA. However, the implementation of this concept in more countries of the Re-

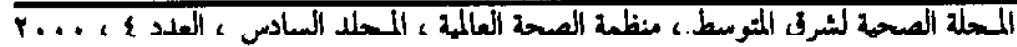


gion needs considerable guidance and support, both managerially and technically. There is a need for a consensus of all stakeholders on a national reproductive health strategy, specifying the appropriate services of each component of reproductive health that can be efficiently delivered at each level of health service delivery [2I]. Moreover, there is a need to improve the quality of existing services, particularly maternal health services, before considering integration and expansion of service provision in some countries of the Region. In most countries, if not all, there is a need to develop comprehensive programmes addressing the reproductive health needs of adolescents and young people.

Some countries like Egypt have integrated occupational health, accidents prevention and chemical safety under one national programme for safety promotion and injury prevention.

Member States of the Region have had a long experience in integrated preventive health care services, such as those addressing vaccine preventable diseases through EPI, or addressing foodborne diseases through integrated food safety programmes. Similarly, management of and control measures for tropical diseases and sexually transmitted diseases have been administratively and technically integrated with considerable success. Recently, the strategy for the integrated management of childhood illness (IMCI) [22] developed by WHO and UNICEF in 1992, which aims to reduce the mortality and morbidity associated with the major causes of childhood illness, has been introduced in eight countries of the Region (Egypt, Islamic Republic of Iran, Iraq, Morocco, Pakistan, Sudan, Syrian Arab Republic and Republic of Yemen): most of them are still in the early implementation phase. However, recent reviews by WHO missions have shown clear indications of increasing interest in the introduction of the IMCI strategy into the national health systems as IMCI activities are planned presently in 15 countries [10].

Some Member States of the Region have integrated health services with medical education. Full integration of these services has been carried out in the Islamic Republic of Iran where both services are integrated at all levels of the national health care system. Some other countries, such as Egypt, Pakistan, Sudan and Syrian Arab Republic, have integrated these services only for special types of health services or in individual geodemographic setups.

\section{Health resources integration}

Integration of health resources, whether technical or financial, depends to a large extent on the adoption of a strict national policy and mechanism that involves and coordinates nationally generated and internationally donated resources for health and other health-related sectors. Such integration should start at the national planning phase through a multisectoral health-related structure, and be directed to achieve the set targets of the national health plan in a complennentary fashion. The technical or financial role of all national partners concerned should be defined, taking into consideration the envisaged or committed resources of the UN as well as bilateral, international or multilateral agencies and NGOs.

Experience in the Region has shown that implementation of the process is easier said than done. Also, it appears that the more meager the health resources are, the better the chances for integration.

The UN and other international agencies have introduced several coordination schemes for partnership at the country level. These include the UN periodic inter- 
agency meetings, the $\mathrm{UN}$ resident coordinator system, the health and other related themes or donor groups, the development assistance group of bilateral donors and UN system and the recently introduced United Nations Development Assistance Framework (UNDAF) [23], which was experienced in 1998 in Morocco and is presently expanding to other countries of the Region. Concommitently, to bring more coherence to UN programmes of assistance at the country level and to prepare for UNDAF, the UN introduced the Common Country Assessment (CCA) [24] participatory process to serve as a tool for reviewing and analysing the national development situation and identifying key issues as a basis for advocacy, policy dialogue and coodinated UN assistance.

At the national level, the "country strategy note" was introduced in the early 1990 s by the UN [25] as a nationally produced and detailed document indicatimg the developmental priorities of each country. This initiative was not responded to positively by most of the Member States in the Region, possibly due to insufficient orientation or a lack of capabilities of the authorities concerned. However, the World Development Report published annually by the World Bank and the World Human Development Report series of UNDP have encouraged some countries in the Region to develop and publish their own national buman development reports. Egypt was the first country in the Region to publish a human development report. It has been published annually by the National Planning Centre since 1992 with a specific priority theme each year. This report has proved to be an efficient tool for identification of needs to be fulfilled and gaps to be bridged for the development of the Egyptian population at central, provincial and district levels. It is often referred to by the Government as well as by the international agencies concerned for directing resources and coordinating outcomes.

Decentralized operation of the integration of national health resources has been practised in the Eastern Mediterranean Region since 1994 with different degrees of success, examples of which are the following.

- Integration of medical and nursing education institutes with those of health services provision.

- Integration of health insurance organization services with public health and medical education institutes as well as the private medical professional sector.

- Cooperation of health authorities and basic education authorities for the development of school health curricula and the promotion of student health as well as environment and health-friendly schools.

- Integration of efforts for the vector control and the control of zoonotic diseases between the public health authorities and those of the agricultural and veterinary sector, as well as the universities.

- Integration of chemical safety and occupational health measures among the ministries of health, industry and labour.

- Coordination and integration between the ministries of health and the ministries of state for environment for the prevention and control of environmental health hazards. 


\section{Reterences}

1. Report of the WHO/UNICEF International Conference on Primary Health Care, Alma-Ata, USSR, 6-12 September 1978, jointly sponsored by the Worid Health Organization and the United Nations Children's Fund. Geneva, World Health Organization, 1978.

2. The work of WHO in the Eastern Mediterranean Region. Annual Report of the Regional Director, 1 January-31 December 1998. Alexandria, World Health Organization Regional Office for the Eastern Mediterranean, 1999.

3. United Nations Devolopment Programme. Human Development Report 1996. Economic growth and human development. Oxford. Oxford University Press, 1996.

4. United Nations Development Programmo. Human devolopment report 1997. Human development to eradicate poverty. Oxford, Oxford University Press, 1997.

5. World Bank. World Bank Report: investing in health. New York, Oxford University Pross, 1993.

6. Murray CJL, Lopez AD, eds. Global burden of disease and injury, Vol. 1. (published on behalf of WHO and the wornd Bank). Cambridge, MA, Harvard University Press, 1996.

7. Berman P. Health sector reform: making health development sustainable. Health policy, 1995, 32(1-3):29-45.

8. Report of the Interregional Meeting on Strengthening District Health Systems Based on Primary Health Care, Harare, Zimbabwe, 3 to 7 August 1987. Geneva, World Health Organization, 1987.

9. Report on the WHO Intercountry Consultation on Basic Development Needs: review and evaluation. Alexandria, World
Health Organization Regional Office for the Eastern Mediterranean, 1996.

10. The work of WHO in the Eastern Mediterranean Region. Annual Report of the Reglonal Director, 1 January-31 December 1999. Alexandria, World Health Organization Regional Office for the Eastern Mediterranean, 2000.

11. Muharram I. Shrouk. The National Programme for Integrated Rural Development. Paper presented at the Second National Conference for Rural Development, Cairo, Egypt, February 1997.

12. Al-Khawashky Mi. The Egyptian experience for school health and environment promotion. Paper presented at the Conference on School Health and Environment Promotion in the Arab Countries, Cairo, Egypt, November 1999.

13. Interregional meeting on the public/private mix in national health systems and the role of ministries of health report, Hacienda Cocoyoc, State of Morelos, Mexico, 22-26 July 1991. Geneva, World Health Organization, 1991.

14. Integrating maternal and child health services with primary health care: practical consideration. Geneva, World Health Or. ganization, 1990.

15. Strengthening maternal and child health programmes through primary health care: guidelines for countries of the Eastern Mediterranean Region based on the deliberations of the Intercountry Meeting on Integration of $\mathrm{MCH}$ into Primary Health Care, Amman, Jordan, 11-15 De. cember 1988. Alexandria, World Health Organization Reglonal Office for the Eastern Mediterranean, 1991 (EMRO Technical Publication, No. 18).

16. Monterio CA et al. Better prospects for child survival. World health forum, 1989 , 10(2):222-7. 
17. Progress report on the safe motherhod initiative. Geneva, World Health Organization, 1989.

18. Mother-baby package: implementing safe motherhood in countries: practical guide. Geneva. World Health Organization, 1996.

19. USAID/Egypt. Population and health activities. Healthy mother/hoalthy child project No. 263-0242, initiated 1995 (http:Iwww.usaid.gov/eg).

20. The Mother Care Egypt Project, 19961998: final report. Arlington, Virginia, John Snow Incorporated, 1998.

21. The reproductive health of adolescents: a strategy for action. A joint WHOI UNFPA/UNICEF statement. Geneva, World Health Organization, 1989.
22. Integrated management of childhood illness, a WHO/UNICEF initiative. Bulletin of the World Health Organization, 1997, 75(suppl. 1).

23. United Nations Development Assistance Framework Guidelines. New York, United Nations, 1999 (www.cca-undaf.org).

24. Common Country Assessment Guidelines. New York, United Nations, 1999 (http://www.cca-undaf.org).

25. United Nations, General Assembly ResoIution A/RES/47/199, 22 December 1992 (triennial review of the operational activities of the United Nations development systom (http://www.un.org/documents/ ga/res/47/a47r199.htm).

\section{AMMOUMCEMENT}

Fifth Suez Canal University Dental Conference 5-7 September 2001

The Faculty of Dentistry, Suez Canal University, Ismalla, Egypt will hold this conference to colncide with the occasion of its first graduation ceremony. The main theme of the conference will be "Women and oral health". The objectlves will be: 1) to provide the particlpants with an understanding of: a) gender-based immune differences and the role of hormonal modulation, b) emerging research on the assoclation of periodontal disease with preterm low birth weight, c) emerging research on the relationship between oral health and osteoporosis and d) the effects of female sex hormone replacement theraples; and 2) to identify various treatment recommendations and their use in evidence-Dased treatment of the remale patlent.

For more information, please contact the conference secretarlat at: Telephone: (206) 4354471 - 381507; Fax: (206) 4354471 ;

Emall: suezdent/st@hotmail.com 